\title{
Article \\ Mechanical Properties of Spark Plasma Sintering-Processed Pure Ti and Ti-6Al-4V Alloys: A Comparative Study between Harmonic and Non-Harmonic Microstructures
}

\author{
Tarik Sadat $^{1, *}$, Kyohei Hayashi ${ }^{2}$ (D) , Gregory Haugou ${ }^{1}$, Herve Morvan ${ }^{1}$ (D), Eric Markiewicz ${ }^{1}$ (D), Laurent Dubar ${ }^{1}$, \\ Maxence Bigerelle $^{1}\left(\mathbb{D}\right.$, Kei Ameyama $^{2} \mathbb{D}$ and Guy Dirras ${ }^{3}$
}

Citation: Sadat, T.; Hayashi, K.; Haugou, G.; Morvan, H.; Markiewicz, E.; Dubar, L.; Bigerelle, M.; Ameyama, K.; Dirras, G. Mechanical Properties of Spark Plasma Sintering-Processed Pure Ti and Ti-6Al-4V Alloys: A Comparative Study between Harmonic and Non-Harmonic Microstructures. Compounds 2021, 1 , 41-57. https://doi.org/10.3390/ compounds1010005

Academic Editor: Bruno Chrcanovic

Received: 1 March 2021

Accepted: 23 March 2021

Published: 17 May 2021

Publisher's Note: MDPI stays neutra with regard to jurisdictional claims in published maps and institutional affiliations.

Copyright: (c) 2021 by the authors. Licensee MDPI, Basel, Switzerland. This article is an open access article distributed under the terms and conditions of the Creative Commons Attribution (CC BY) license (https:/ / creativecommons.org/licenses/by/ $4.0 /)$.
1 Laboratoire d'Automatique, de Mécanique et d'Informatique Industrielles et Humaines, LAMIH, Université Polytechnique Hauts-de-France, UMR CNRS 8201, 59300 Valenciennes, France; gregory.haugou@uphf.fr (G.H.); herve.morvan@uphf.fr (H.M.); eric.markiewicz@uphf.fr (E.M.); laurent.dubar@uphf.fr (L.D.); maxence.bigerelle@uphf.fr (M.B.)

2 Department of Mechanical Engineering 1-1-1 Noji-higashi, Ritsumeikan University, Kusatsu, Shiga 5258577, Japan; rm0112ih@ed.ritsumei.ac.jp (K.H.); ameyama@se.ritsumei.ac.jp (K.A.)

3 Laboratoire des Sciences des Procédés et des Matériaux, LSPM, Université Sorbonne Paris Nord, CNRS-UPR 3407, 99 Avenue Jean-Baptiste Clément, 93430 Villetaneuse, France; dirras@lspm.cnrs.fr

* Correspondence: tarik.sadat@uphf.fr

\begin{abstract}
Microstructure characteristics and compressive property relationships of so-called harmonic (composed by fine and coarse grains) and conventional pure titanium (Ti) and Ti-6Al-4V alloy processed by powder metallurgy route are presented in the present work. Electron backscatter diffraction (EBSD) analysis was performed to characterize the as-processed microstructures. The harmonicity structure of selected samples is described, and relevant EBSD maps are presented. The bulk samples' hardness is reported, along with compressive responses at quasi-static and intermediate strain rates, ranging from $0.005 \mathrm{~s}^{-1}$ to $16 \mathrm{~s}^{-1}$. The strain rate sensitivity of these metallic samples is discussed, and the benefits in terms of mechanical properties of the harmonic microstructures compared with the non-harmonic conventional ones are highlighted. Finally, a modified Johnson-Cook model was shown to predict fairly the experimental results.
\end{abstract}

Keywords: titanium; titanium alloys; microstructure; harmonic structure; compression tests; constitutive modeling

\section{Introduction}

$\mathrm{Ti}$ and Ti-6Al-4V alloys are widely used in several fields (aeronautics, biomedical applications, nuclear energy) as functional materials due, for example, to their low density and good corrosion resistance [1-3]. Ti-6Al-4V alloys belong to the $\alpha+\beta$ alloy [4]. A commonly used method to improve polycrystalline metals and alloys' strength characteristics is grain refinement [5] via the well-known Hall-Petch law [6,7] that correlates the inverse of the square root of the grain size $d$ to the yield strength $\sigma_{\mathrm{y}}$ (or hardness) and $\sigma_{0}$ (a material constant) as follows:

$$
\sigma_{\mathrm{y}}=\sigma_{0}+\frac{k}{\sqrt{d}}
$$

The Hall-Petch coefficient $k$ represents the grain boundaries contribution to the yield strength of a metallic sample [8].

An increase of the mechanical resistance and/or the flow stress of metals leads quite often to a decrease of the ductility. To avoid such loss, several approaches were considered such as severe plastic deformation (SPD) techniques [9] or combining extrusion machining and heat treatment [10]. Bimodal microstructures (or presenting gradient microstructure) were also elaborated or considered to obtain good mechanical properties-ductility compromise [8,11-13]. In this context, powder metallurgy (PM) route consisting of coupling 
mechanical milling (MM) of pure Ti or Ti-6Al-4V powders and spark plasma sintering (SPS) was suitable for preparing bulk Ti and Ti-6Al-4V alloys having a tailored bimodal microstructure $[14,15]$. When the parameters of MM and SPS are optimized, such a process leads to a microstructural design concept called "harmonic structure" (HS). Indeed, due to the MM process, the initial powder surface is modified. From a spherical shape, it evolves to an irregular one. Cross-sectional scanning electron microscopy (SEM) micrographs of the milled powders show outer and inner regions [14]. The outer region, the thickness of which can be controlled during the MM process (milling time), is strongly deformed and contains a high density of structural defects (dislocations, point defects), unlike the internal region in which the stored energy is low. During the SPS, elevated dwell temperature induces the recrystallization phenomenon. Indeed, the external zone with the most stored energy will generate tiny grains (the shell), unlike the particle's internal area (the core). Subsequently, SPS sintering will consolidate all of the powder by creating an interconnected network of the different particles' shells. This mechanism leads to a so-called harmonic structure [16-19].

The HS enhanced mechanical properties were attributed to the distribution of mainly fine grains and others that are mainly coarse. Harmonic microstructures lead to a homogeneous distribution of strain, while plastic activity occurs and avert plastic deformation localization due to an accommodation of plastic deformation induced by the strain distribution in the coarse grains domains, which lead to an accommodation of work hardening to large strain values $[20,21]$. All the studies carried out to date have shown that harmonic structures improved mechanical properties compared to conventional fine-grained or ultra-fine microstructures [20-25]. In particular, a much better synergy between mechanical strength and ductility was observed $[18,21]$. This results from the microstructure's heterogeneous character, which induces the delocalization of the deformation due to the grain size gradient [26], thus delaying the plastic instability during uniaxial tensile tests, for example [17]. This tendency seems to be a characteristic common to heterogeneous microstructures [27-30]. Indeed, as revealed by the available literature, heterogeneous microstructures are known to induce better mechanical properties compromise, due to the presence of long-range stresses, themselves induced by the presence of geometrically necessary dislocations due to incompatibilities of deformation.

In this work, compression tests of harmonic samples (designed by coupling MM and SPS) and non-harmonic ones (designed by SPS only) of Ti and Ti-6Al-4V are investigated considering three strain rates. The effect of the initial microstructures on the mechanical properties is discussed, and the strain rates influence presented. Two models of plastic flow behavior were examined and compared with the experimental results.

\section{Materials and Methods}

Ti and Ti-6Al-4V alloys were all designed by the SPS process from a powder metallurgy route as originally proposed and developed by Prof. K. Ameyama's group [16-19,31]. By coupling MM and SPS process, HS samples can be obtained, compared to only considering SPS, which leads to conventional homogeneous or bimodal microstructures. The SPS is a PM process allowing high processing versatility [1]. SPS method (also known as field assisted sintering technology (FAST) is a fast-sintering process. Initial powders of metal or ceramic are placed in a graphite die and then a uniaxial pressure is applied during sintering [32]. For example, bulk Ni-W alloys can be successfully sintered from blends of high-purity $\mathrm{Ni}$ and $\mathrm{W}$ powders (W amount ranged from 10 to $65 \mathrm{wt} . \%$ ) during a relatively short time and lead to fully densified samples [12,33-35]. Two Ti and three Ti-6Al-4V samples will be considered in this work. The first set of two samples was obtained from initial unmilled Ti and Ti-6Al-4V powders (IP) referred to as Ti-IP and Ti-6Al-4V-IP. The chemical composition of the powders is presented in Table 1. 
Table 1. Chemical composition of the Ti and Ti-6Al-4V initial powders (mass \%).

\begin{tabular}{ccccccccc}
\hline Powder & Al & $\mathbf{V}$ & $\mathbf{F e}$ & $\mathbf{H}$ & $\mathbf{N}$ & $\mathbf{O}$ & $\mathbf{C}$ & $\mathbf{T i}$ \\
\hline $\mathrm{Ti}$ & - & - & 0.04 & 0.012 & 0.015 & 0.111 & 0.004 & bal. \\
\hline Ti-6Al-4V & 6.24 & 4.1 & 0.1 & 0.002 & 0.005 & 0.108 & 0.024 & bal. \\
\hline
\end{tabular}

The second set of three samples was made from room temperature (RT) mechanically milled (MM) powders under Ar flow, using planetary ball milling (Fritsch P-5). Depending on the microstructure characteristics to be fabricated, different milling times were considered, such as 90, 180, and $360 \mathrm{ks}$. The resulting MM powders are referred to as Ti6Al-4V-MM-90 ks, Ti-6Al-4V-MM-180 ks, and Ti-MM-360 ks, respectively. The combination of MM and SPS processes leads to samples with an HS design composed of coarse-grained regions (core) and a rim of fine-grained regions (shell) as described elsewhere [16-19,22]. The sintering parameters were as follows for all samples: applied uniaxial pressure of $50 \mathrm{MPa}$ for half an hour considering a dwell temperature of $800{ }^{\circ} \mathrm{C}$. An SPS 510-ML by NJS was considered.

After the sintering process, SPS pellets dimensions were such that the diameter and thickness of 15 and $3.5 \mathrm{~mm}$, respectively, were obtained. The density of the samples was measured by the Archimedes method using an Ohaus Voyager Pro ${ }^{\circledR}$. Samples cut from the pellets were first mechanically mirror-polished and then electrochemically polished using A2 electrolytic solution using a LectroPol- $5^{\circledR}$ electropolishing apparatus from Struers (Copenhagen, Denmark). Scanning electron microscope and EBSD (electron backscatter diffraction) analyses were all realized with a JEOL JSM-7100F apparatus (Tokyo, Japan). A voltage of $15 \mathrm{kV}$ was fixed. The step size was fixed to $0.1 \mu \mathrm{m}$ for all the $2 \mathrm{D}$ acquisitions. EBSD data were then analyzed using HKL Channel 5 software and the AZTec (UK) software, both from OXFORD Instruments (Oxford, UK). Vickers microhardness (HV) tests were performed using a Future Tech ${ }^{\circledR}$ microhardness tester (Model FM) (Future-Tech Corp., Kawasaki, Japan) under a $1000 \mathrm{gf}$ load applied during $20 \mathrm{~s}$. To get more reliable results, 20 measurements were done on each sample. Compression tests were finally performed on two different apparatus. Quasi-static tests $\left(\dot{\varepsilon}=0.005 \mathrm{~s}^{-1}\right)$ were performed using a Sintech 20D apparatus. A Rudolph XR200 (H.D. Rudolph GmbH, Reinheim, Germany) electro-optical extensometer was used to track the deformation. A Yokogawa DL750-10 $\mathrm{MHz}$ (Yokogawa Electric Corporation, Tokyo, Japan) was used to record the signals. A maximum force of $100 \mathrm{kN}$ can be considered and a constant displacement is applied. Finally, intermediate strain rates were performed using an Instron VHS65/20 (Instron, Norwood, MA, USA).

Compression tests were all performed on cylinders that present diameter of about $3 \mathrm{~mm}$ and a height of about $3.5 \mathrm{~mm}$ prepared from the as-sintered cylinders. All tests were reproduced three times, and the averages are presented in this work. Home-made programs written in Python language, and Matlab ${ }^{\circledR}$ were both used to analyze data from compression tests.

\section{Choice of a Constitutive Mathematical Model}

It is always useful to have simple analytical models (but with sufficient accuracy for engineering applications) to describe a set of experimental behaviors [36-41]. Several constitutive material models were proposed in the literature (Johnson-Cook [19], Bammann-Chiesa-Johnson [42], Zerilli-Armstrong [43], Bodner-Partom [44] models ... ). In this work, we examined two such phenomenological models, namely, the Johnson-Cook (JC) model [45] and a modified Johnson-Cook (MJC) model [46], which were developed for general metals. They are here employed for the first time (to the best of our knowledge) to describe the compression behavior of harmonic materials (five studied titanium and titanium alloys). 


\section{Results and Discussions}

The results presented herein were obtained with the operating conditions given in Table 2. As it is seen, the same holding time and applied pressure were considered for all the samples during the SPS process. Notice that after the SPS process, high density of more than $99 \%$ of theoretical density was obtained in all samples.

Table 2. Processing conditions of the samples.

\begin{tabular}{ccccc}
\hline Sample Name & $\begin{array}{c}\text { Milling Time of the } \\
\text { Powder (ks) }\end{array}$ & $\begin{array}{c}\text { Spark Plasma } \\
\text { Sintering (SPS) } \\
\text { Holding Time (ks) }\end{array}$ & $\begin{array}{c}\text { Applied Pressure } \\
\text { during the SPS } \\
\text { Process (MPa) }\end{array}$ & $\begin{array}{c}\text { Density of the Sample } \\
(\mathbf{g} \cdot \mathbf{c m}-\mathbf{3})\end{array}$ \\
\hline Ti-IP & - & 1.8 & 50 & 4.55 \\
\hline Ti-MM-360 ks & 360 & 1.8 & 50 & 4.52 \\
\hline Ti-6Al-4V-IP & - & 1.8 & 50 & 4.39 \\
\hline Ti-6Al-4V-MM-90 ks & 90 & 1.8 & 50 & 4.36 \\
\hline Ti-6Al-4V-MM-180 ks & 180 & 1.8 & 50 & 4.36 \\
\hline
\end{tabular}

\subsection{Microstructural Characterization}

To begin with the microstructure, we first present in Figure 1 the inverse pole figures (IPF) of the as-processed samples. Polycrystalline pure Ti samples were composed of the $\alpha$-hexagonal close-packed (hcp) phase [47]. IPF maps of the pure Ti-IP (Figure 1a) and the Ti-MM-360 ks (Figure 1b) illustrate that the Ti-IP highlighted a larger grain size than the Ti-MM-360 ks one. Indeed, the MM process reduced the mean grain size of the Ti-MM-360 ks $(12.2 \mu \mathrm{m})$ compared with the non-milled sample $(24.3 \mu \mathrm{m})$. It can also be noticed that a bimodality of the grain size distribution occured in this mechanically milled pure Ti sample. Moreover, in both cases, the microstructures did not present any preferential orientation of the grains, which were thus randomly oriented.

Polycrystalline Ti-6Al-4V alloys were composed of a hexagonal close-packed phase and a body-centered cubic one [48,49]. IPF maps of the Ti-6Al-4V alloys are gathered in Figure 1c-e. The average grain size of the Ti-6Al-4V-IP (Figure 1c) alloy was $2.8 \mu \mathrm{m}$ versus $1.7 \mu \mathrm{m}$ for Ti-6Al-4V-MM-180 ks (Figure 1d) and Ti-6Al-4V-MM-90 ks (Figure 1e). Ti-6Al-4V-IP displayed an equiaxial and lamellar microstructure, while the milled alloys (MM-90 ks and MM-180 ks) displayed only an equiaxial one. In all cases, the grains were also randomly oriented. It was interesting to notice that in the two mechanically milled Ti-6Al-4V samples, the fine grains surrounded the coarse ones [22].

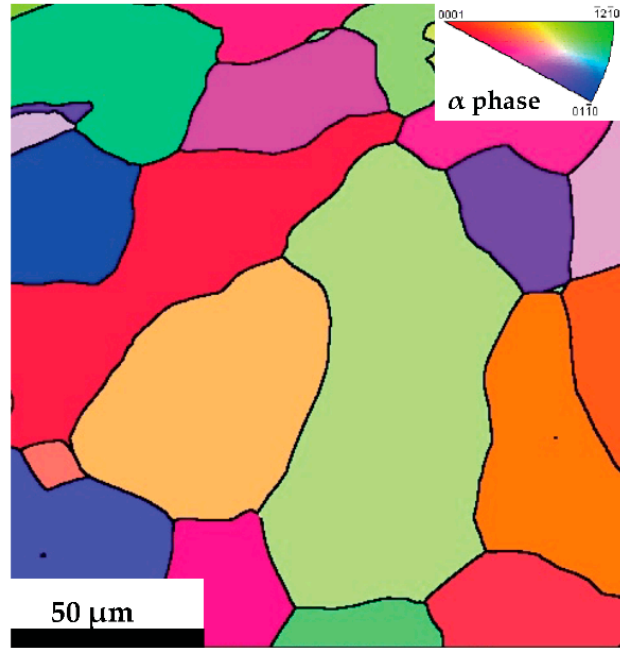

(a)

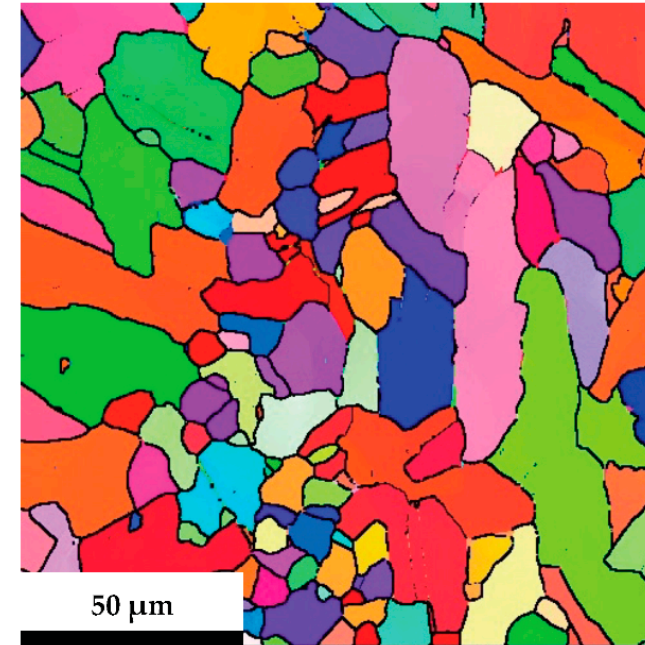

(b)

Figure 1. Cont. 


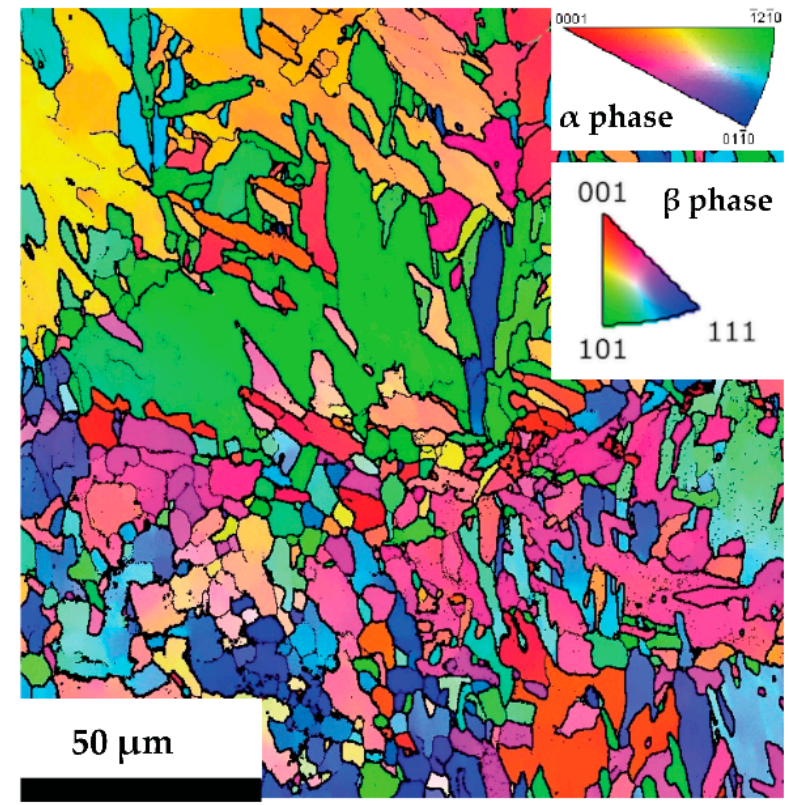

(c)

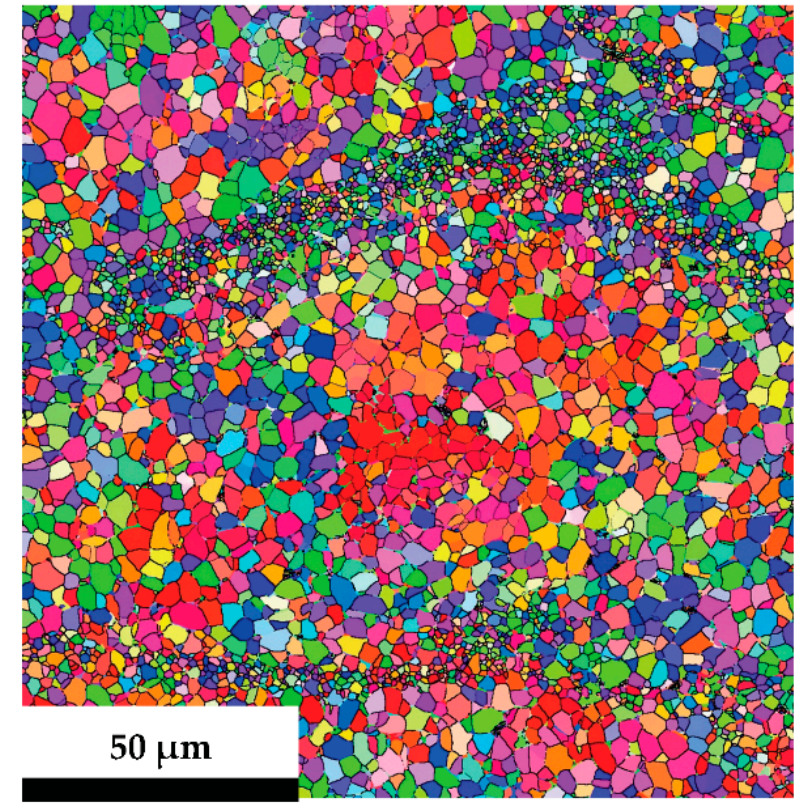

(d)

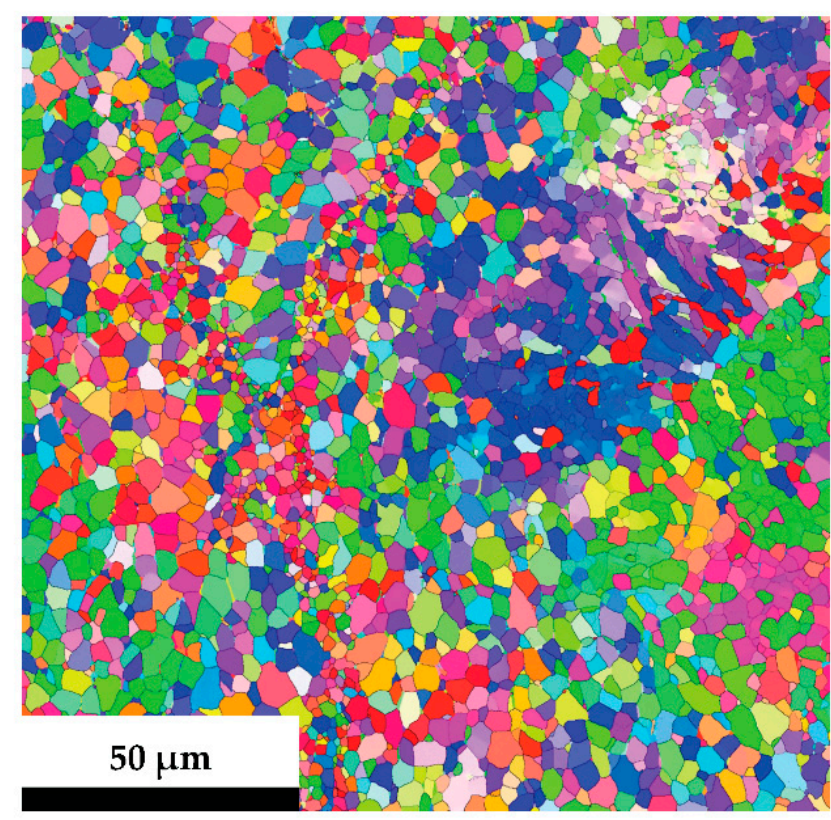

(e)

Figure 1. Inverse pole figures (IPF) maps of (a) Ti-IP, (b) Ti-MM-360 ks, (c) Ti-6Al-4V-IP, (d) Ti-6Al-4V-MM-180 ks, and (e) Ti-6Al-4V-MM-90 ks.

\subsection{Mechanical Properties \\ 3.2.1. Vickers Hardness}

Vickers hardness results are presented in Figure 2. As expected, pure titanium displayed lower hardness than Ti-6Al-4V alloys. The hardness difference between Ti-IP and Ti-MM-360 ks was due to the average grain size. Indeed, hardness decreases with grain size [50]. Finally, the two Ti-6Al-4V-MM alloys showed a slightly greater mean hardness than Ti-6Al-4V IP sample; here again, the difference in grain sizes seemed to be the main reason. 


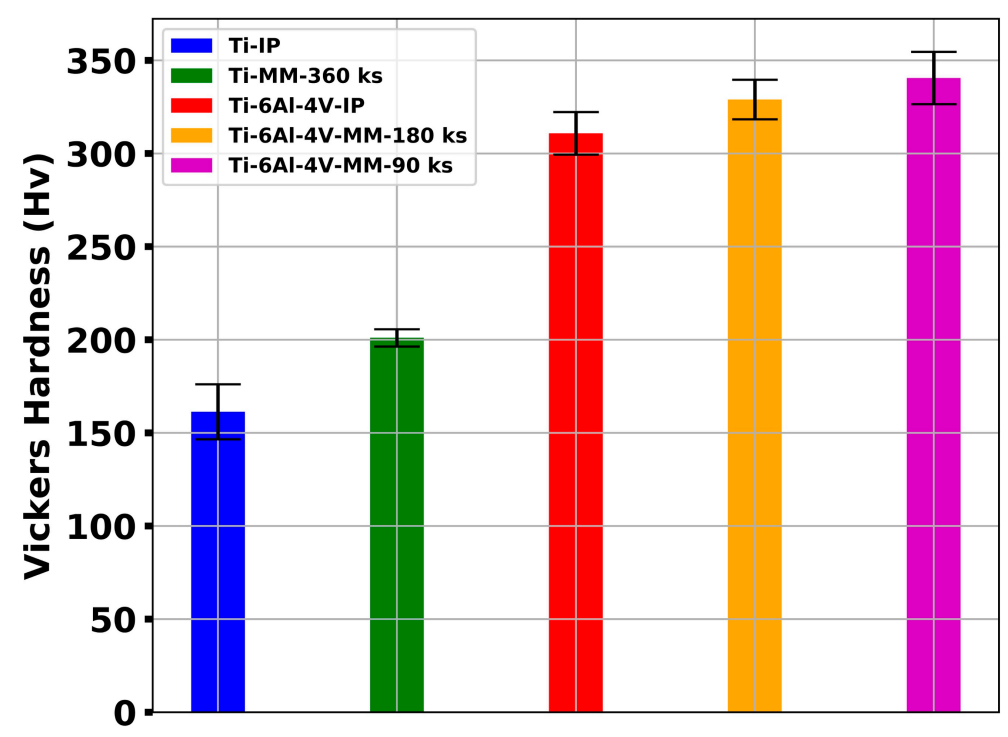

Figure 2. Vickers hardness of the samples (mean value \pm standard deviation).

\subsubsection{Compression Tests}

During the compression tests, three strain rates were considered $\left(\dot{\varepsilon}=0.005 \mathrm{~s}^{-1}, 0.3 \mathrm{~s}^{-1}\right.$, and $16 \mathrm{~s}^{-1}$ ). The results of quasi-static are shown in Figure 3 and intermediate strain rate tests are shown in Figures 4 and 5. Pure Ti samples highlight inferior mechanical properties compared to the Ti-6Al-4V alloys. This is partly due to the advantages of the alloying of titanium [51] and the grain size difference. It was observed that HS samples exhibited a higher yield strength and flow stress as compared with the non-harmonic ones. Furthermore, the pure Ti-IP sample had the lowest mechanical properties, while the Ti-6Al-4V-MM-90 ks displayed the highest ones, whatever the strain rate. This means that milling during $90 \mathrm{ks}$ the initial powder was enough to increase the mechanical properties of the Ti-6Al-4V alloy sintered by SPS compared with the Ti-6Al-4V-180 ks. The shape of the compression curves of the Ti-6Al-4V alloys at a strain rate of $16 \mathrm{~s}^{-1}$ was not the same as the ones at $0.005 \mathrm{~s}^{-1}$ and $0.3 \mathrm{~s}^{-1}$. Indeed, from approximately $10 \%$ of the strain, a plateau occurred at a strain rate of $16 \mathrm{~s}^{-1}$ (Figure 5) due to a work hardening difference.

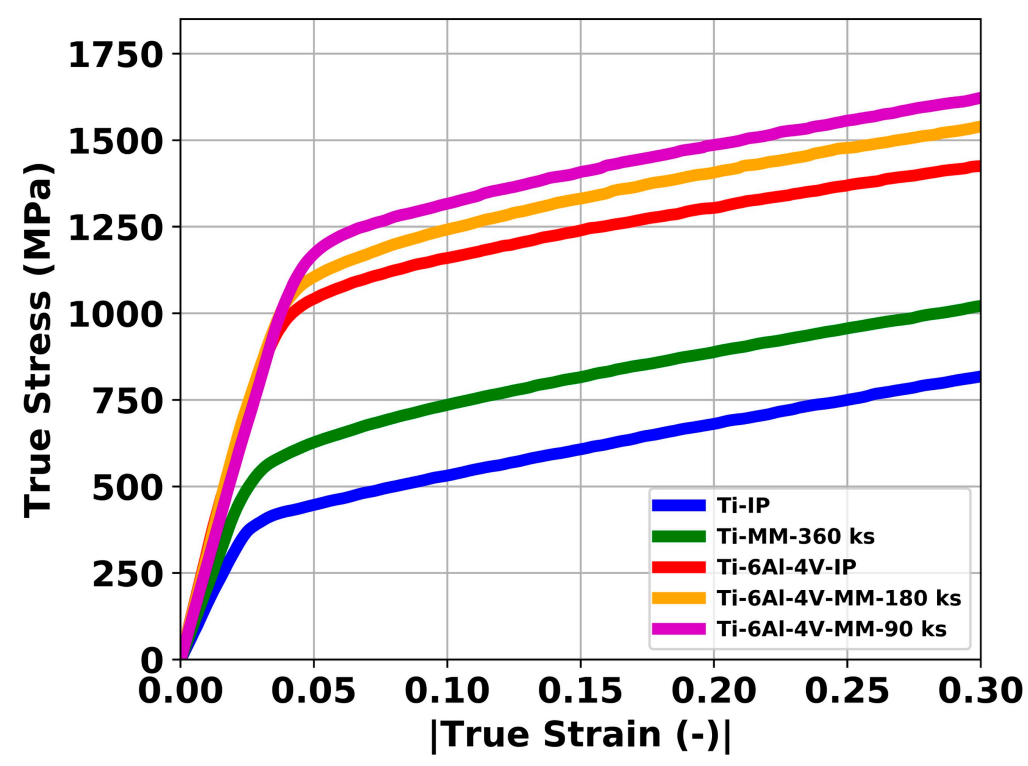

Figure 3. True stress versus true strain $\left(\dot{\varepsilon}=0.005 \mathrm{~s}^{-1}\right)$. 


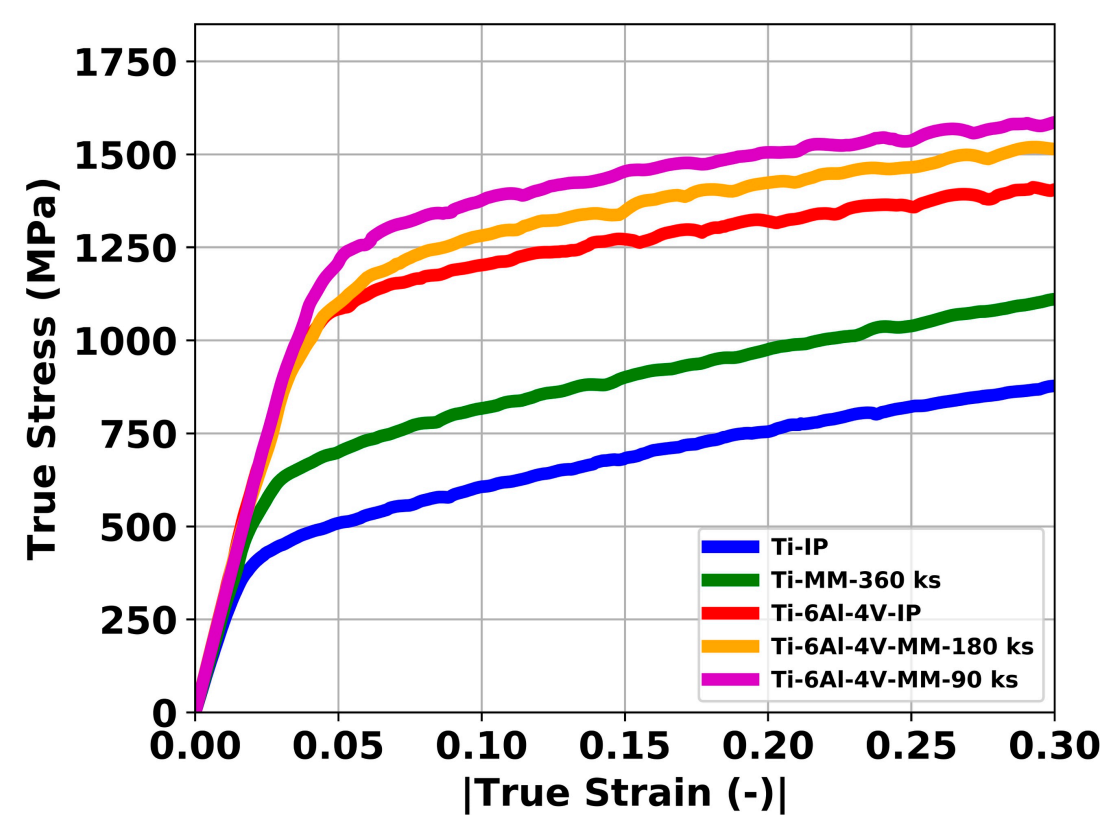

Figure 4. True stress versus true strain $\left(\dot{\varepsilon}=0.3 \mathrm{~s}^{-1}\right)$.

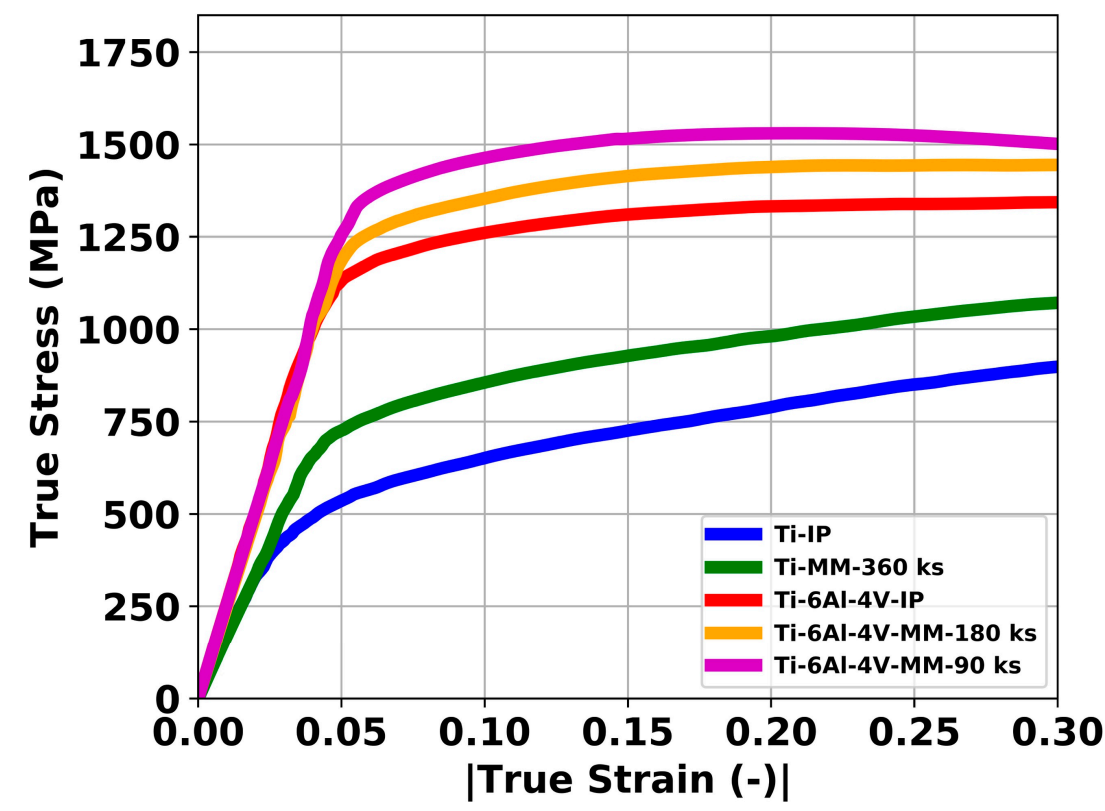

Figure 5. True stress versus true strain $\left(\dot{\varepsilon}=16 \mathrm{~s}^{-1}\right)$.

\subsection{Strain Rate Sensitivity}

To determine strain rate effects on flow behaviors of our samples, strain rate sensitivity (SRS) is computed. The well-known power-law equation [52] presented in Equation (2) was considered:

$$
\sigma=C \dot{\varepsilon}^{m}
$$

where $m$ is the SRS exponent, $\dot{\varepsilon}$ the strain rate, $\sigma$ is the applied flow stress, and $C$ a constant. $0.2 \%$ offset yield strength $\left(\sigma_{0.2}\right)$ versus the initial strain rate is presented in logarithmic scale in Figure 6. An increase of the $\sigma_{0.2}$ as a function of the strain rate was observed. A fairly good linear relationship was seen in the double-log scale considering Equation (2). Each slope in this figure corresponds to the SRS exponent, $m$ value. Regarding the pure Ti, $m$ is equal to 0.025 for the Ti-IP and 0.028 for the Ti-MM-360 ks. Lower values of $m$ are obtained with the alloys, namely, 0.016 (for the Ti-6Al-4V-IP and Ti-6Al-4V-MM-180 ks) and 0.017 
(for the Ti-6Al-4V-MM-90 ks). These values of SRS exponents are in accordance with $m$ values of Ti and Ti-6Al-4V samples given in the literature [53,54]. It is interesting to notice that the microstructures of IP and MM samples do not significantly influence the SRS.

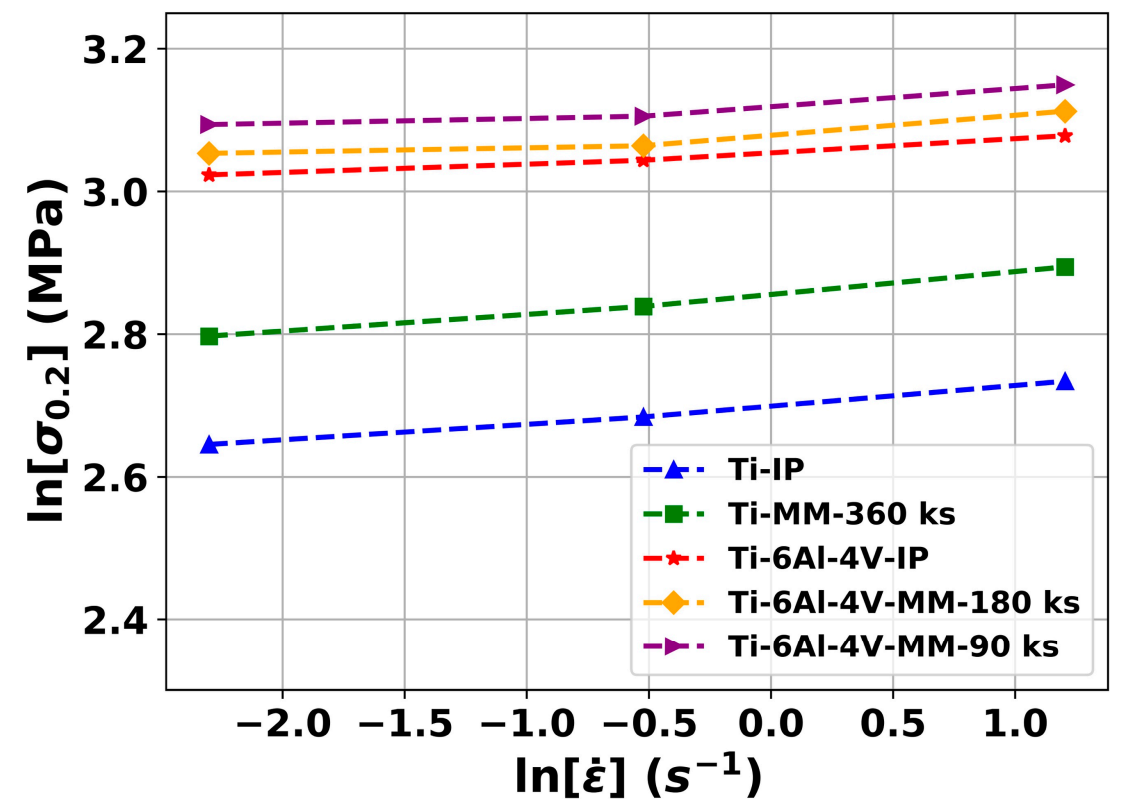

Figure 6. Evolution of $\ln \left(\sigma_{0.2}\right)$ as a function of $\ln (\dot{\varepsilon})$.

\subsection{Constitutive Modeling}

\subsubsection{Johnson-Cook Model}

The conventional Johnson-Cook (JC) model [19] uses the following formula:

$$
\sigma=\left\{\left(A+B \varepsilon_{\mathrm{p}}^{n}\right)\left(1+C \ln \frac{\dot{\varepsilon}}{\dot{\varepsilon}_{0}}\right)\right\} \times\left(1-\left(\frac{T-T_{\mathrm{r}}}{T_{\mathrm{m}}-T_{\mathrm{r}}}\right)^{m}\right)
$$

where $\bar{\sigma}$ is the equivalent plastic stress. $A, B, C, n$, and $m$ are material parameters. $\varepsilon_{\mathrm{p}}, \dot{\varepsilon}$, and $\dot{\varepsilon}_{0}$ represent the plastic strain and the considered and reference strain rates, respectively. $T_{\mathrm{m}}$ and $T_{\mathrm{r}}$ are the melting and reference temperatures. This model is quite easy to use and appropriate to describe the plastic behavior of samples [37,45,55].

All the compression tests were performed under room temperature. We can therefore neglect the thermal softening effect, Equation (3) was then modified to:

$$
\sigma=\left\{\left(A+B \varepsilon_{\mathrm{p}}^{n}\right)\left(1+C \ln \frac{\dot{\varepsilon}}{\dot{\varepsilon}_{0}}\right)\right\}
$$

The value of reference strain rate $\dot{\varepsilon}_{0}$ was $0.005 \mathrm{~s}^{-1}$. Four parameters $(A, B, n$, and $C)$ were required in the fitting stress-strain curves, using Equation (4). To determinate $A, B$, and $n$ values, for a value $\dot{\varepsilon}=0.005 \mathrm{~s}^{-1}$, Equation (4) was transformed into:

$$
\sigma=\left(A+B \varepsilon_{\mathrm{p}}^{n}\right)
$$

From Equation (5), parameters $A, B$, and $n$ were then computed from the $\sigma-\varepsilon$ curves obtained at the reference strain rate $\left(\dot{\varepsilon}=0.005 \mathrm{~s}^{-1}\right)$. Parameter $C$ was acquired from the fitting curves with other values of $\dot{\varepsilon}$. JC constitutive model parameters are shown in Table 3 . 
Table 3. Johnson-Cook (JC) constitutive model parameters of the samples.

\begin{tabular}{ccccc}
\hline Parameter & $\boldsymbol{A} \mathbf{( M P a )}$ & $\boldsymbol{B} \mathbf{( M P a )}$ & $\boldsymbol{n}$ & $\boldsymbol{C}$ \\
\hline Ti-IP & 433 & 2016 & 1.323 & 0.020 \\
\hline Ti-MM-360 ks & 590 & 1562 & 1.043 & 0.010 \\
\hline Ti-6Al-4V-IP & 997 & 1537 & 0.992 & 0.011 \\
\hline Ti-6Al-4V-MM-90 ks & 1080 & 1561 & 0.976 & 0.013 \\
\hline Ti-6Al-4V-MM-180 ks & 1217 & 1880 & 1.173 & 0.013 \\
\hline
\end{tabular}

\subsubsection{Modified Johnson-Cook Model}

More recently, Wang et al. [46] performed experimental tests to study the mechanical behaviors of Mg-Al-4Y alloys. They found that the JC model results led to a significant variation from their experimental data. Hence, they proposed a modified model (MJC), providing improved results. The MJC model [46] formula is:

$$
\sigma=\left\{\left(A+B_{1} \varepsilon_{\mathrm{p}}\right)\left(1+C_{1} \ln \frac{\dot{\varepsilon}}{\dot{\varepsilon}_{0}}\right)+B_{2}\left(1+C_{2} \ln \frac{\dot{\varepsilon}}{\dot{\varepsilon}_{0}}\right) \varepsilon_{\mathrm{p}}^{2}+\left(D+\ln \varepsilon_{\mathrm{p}}\right) \ln \frac{\dot{\varepsilon}}{\dot{\varepsilon}_{0}}\right\} \times\left(1-\left(\frac{T-T_{\mathrm{r}}}{T_{\mathrm{m}}-T_{\mathrm{r}}}\right)^{m}\right)
$$

where $A, B_{1}, B_{2}, C_{1}, C_{2}, D$, and $m$ are material coefficients having the same meaning as in the Johnson-Cook model. We, therefore, implemented this model with a very slight variation. Indeed, given that all our compression tests were performed under RT, we have neglected the influence of temperature (softening effect). Equation (6) was therefore simplified to:

$$
\sigma=\left\{\left(A+B_{1} \varepsilon_{\mathrm{p}}\right)\left(1+C_{1} \ln \frac{\dot{\varepsilon}}{\dot{\varepsilon}_{0}}\right)+B_{2}\left(1+C_{2} \ln \frac{\dot{\varepsilon}}{\dot{\varepsilon}_{0}}\right) \varepsilon_{\mathrm{p}}^{2}+\left(D+\ln \varepsilon_{\mathrm{p}}\right) \ln \frac{\dot{\varepsilon}}{\dot{\varepsilon}_{0}}\right\}
$$

Notice that when $\dot{\varepsilon}_{0}=0.005 \mathrm{~s}^{-1}$, Equation (7) simplifies to:

$$
\sigma=A+B_{1} \varepsilon_{\mathrm{p}}+B_{2} \varepsilon_{\mathrm{p}}^{2}
$$

A two-order polynomial fitting of the $\sigma-\varepsilon$ curves leads to the value of $A, B_{1}$, and $B_{2}$. Considering $\dot{\varepsilon}=16 \mathrm{~s}^{-1}, C_{1}, C_{2}$, and $D$ parameters were calculated.

The final parameter values $A, B_{1}, B_{2}, C_{1}, C_{2}$, and $D$ obtained are shown in Table 4 .

Table 4. Modified Johnson-Cook constitutive model parameters of the samples.

\begin{tabular}{ccccccc}
\hline Parameter & $\boldsymbol{A} \mathbf{( M P a )}$ & $\boldsymbol{B}_{\mathbf{1}}$ & $\boldsymbol{B}_{\mathbf{2}}$ & $\boldsymbol{C}_{\mathbf{1}}$ & $\boldsymbol{C}_{\mathbf{2}}$ & $\boldsymbol{D}$ \\
\hline Ti-IP & 400 & 1426 & -260.5 & 0.036 & 0.648 & -2.563 \\
\hline Ti-MM-360 ks & 590 & 1539 & -509.3 & 0.023 & 0.353 & 1.135 \\
\hline Ti-6Al-4V-IP & 954 & 2155 & -1923 & -0.01 & 0.132 & 29.182 \\
\hline Ti-6Al-4V-MM-90 ks & 1023 & 2268 & -1776 & -0.08 & -0.037 & 134.697 \\
\hline Ti-6Al-4V-MM-180 ks & 1109 & 2224 & -1713.3 & -0.003 & 0.238 & 23.35 \\
\hline
\end{tabular}

Experimental results and computed flow stress by the Johnson-Cook model comparisons are shown in Figure 7. It can be seen that this model was not well adapted to our experimental data points for strain rates of $0.3 \mathrm{~s}^{-1}$ and $16 \mathrm{~s}^{-1}$. However, for a strain rate of $0.005 \mathrm{~s}^{-1}$, the correlation was much more pronounced. The results of the model and the best experimental line are drawn in Figure 8; most recovered data points for the two highest strain rates $\left(0.3 \mathrm{~s}^{-1}\right.$ and $\left.16 \mathrm{~s}^{-1}\right)$ were not sufficiently close to the best line. Therefore, the conventional JC model cannot be selected. 


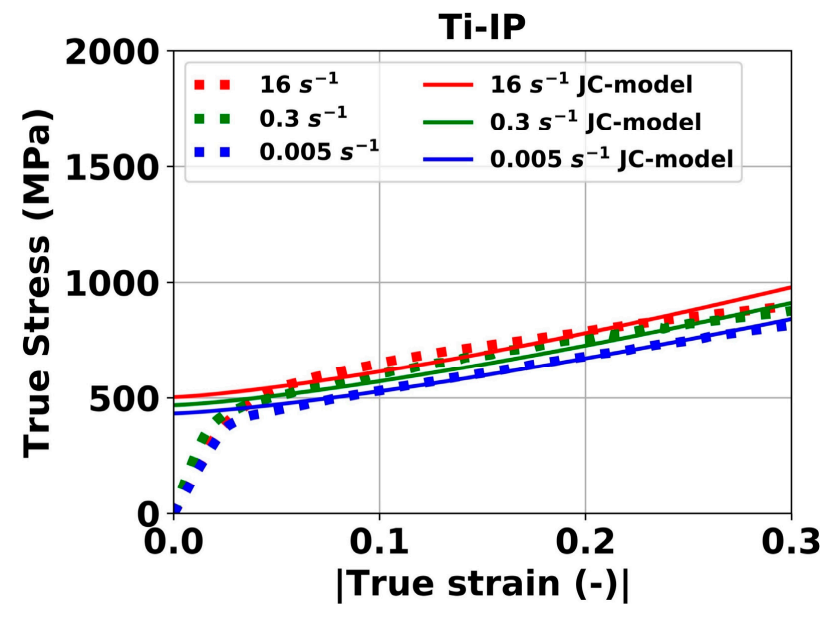

(a)

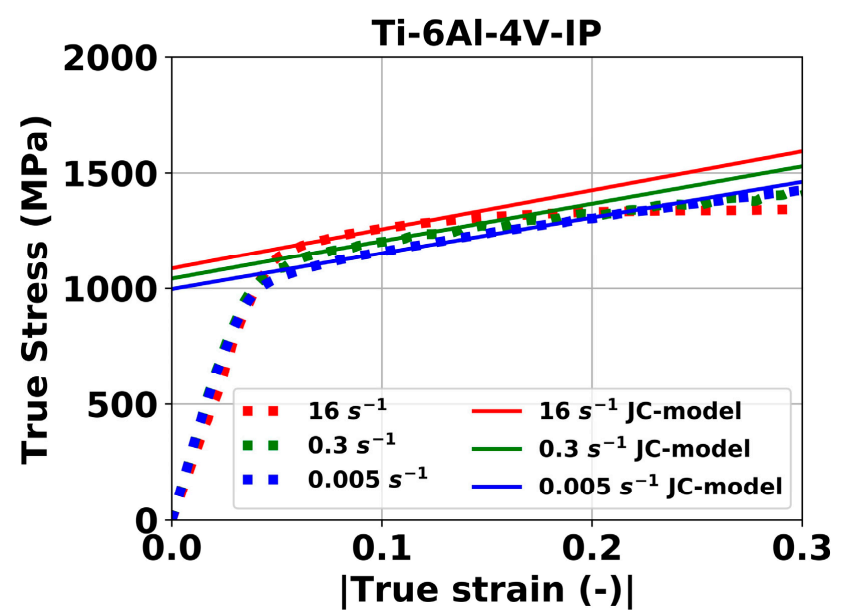

(c)

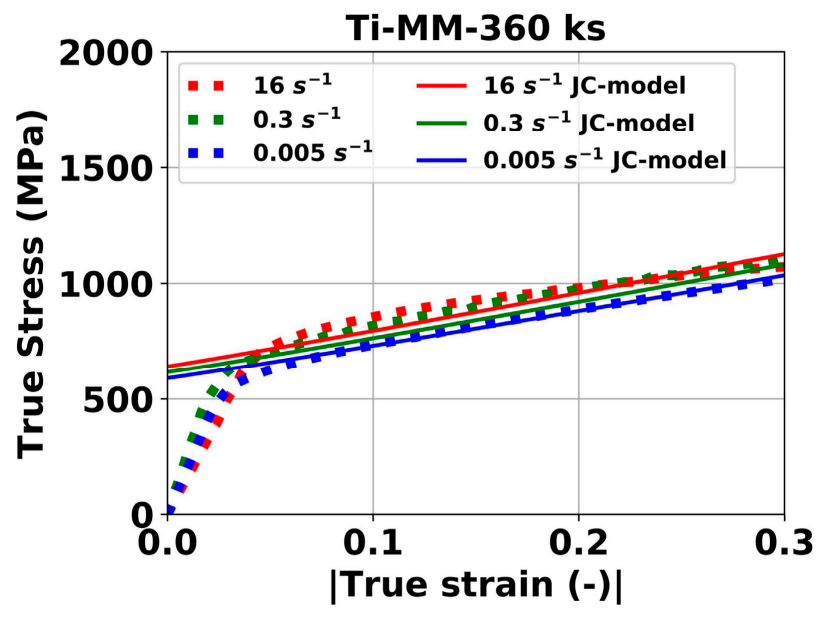

(b)

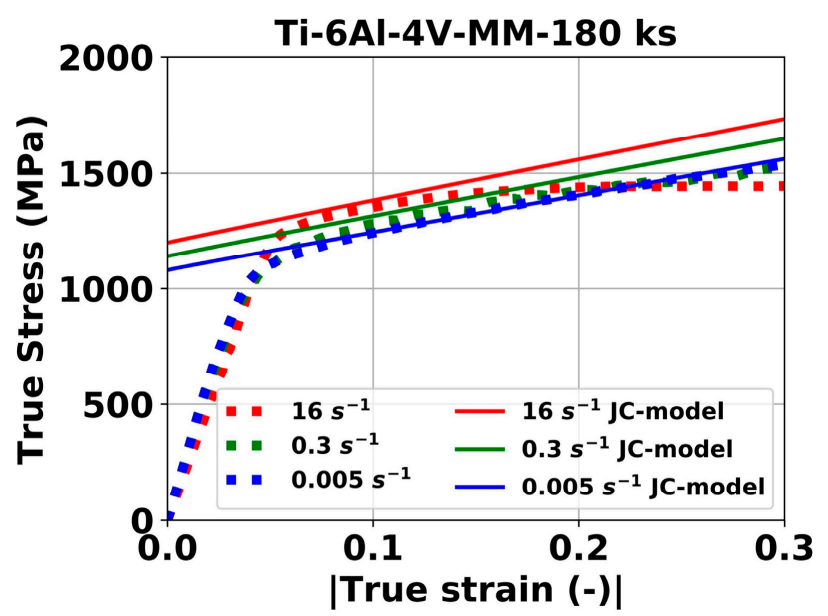

(d)

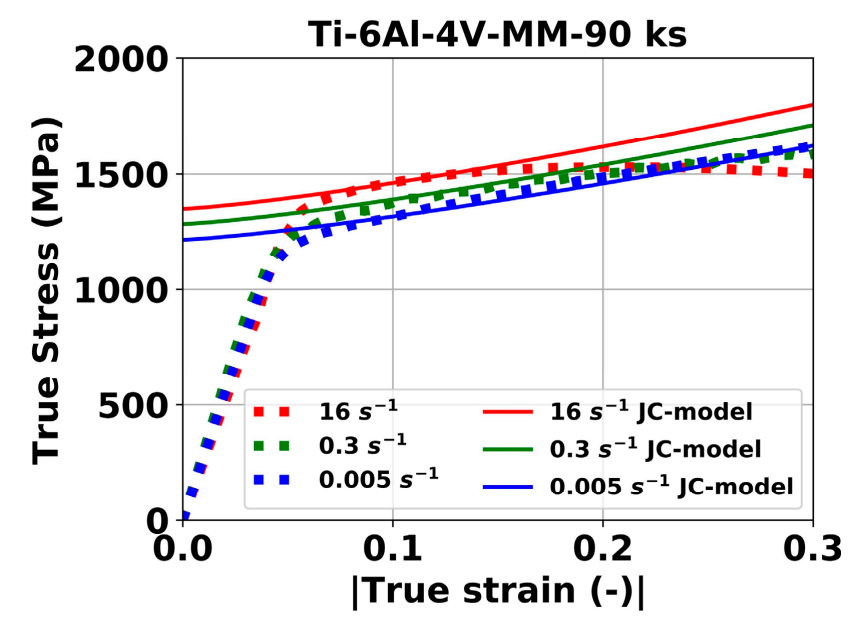

(e)

Figure 7. Experimental (squares) and computed (continuous line) flow stresses by the JC model of (a) Ti-IP, (b) Ti-MM-360 ks, (c) Ti-6Al-4V-IP, (d) Ti-6Al-4V-MM-180 ks, and (e) Ti-6Al-4V-MM-90 ks. 


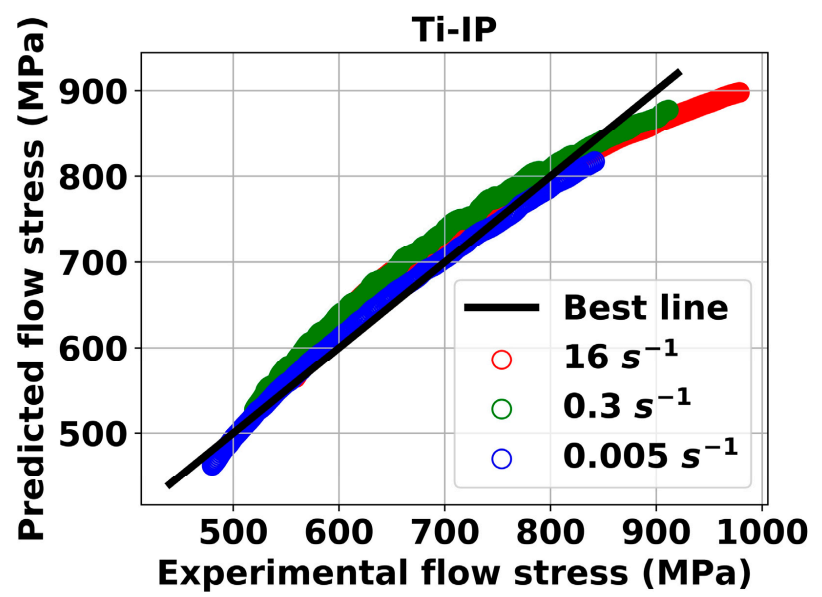

(a)

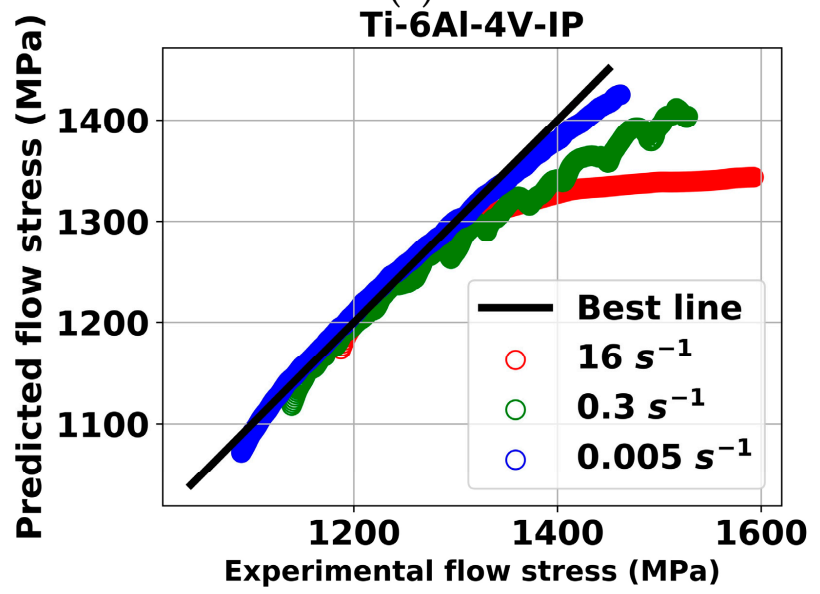

(c)

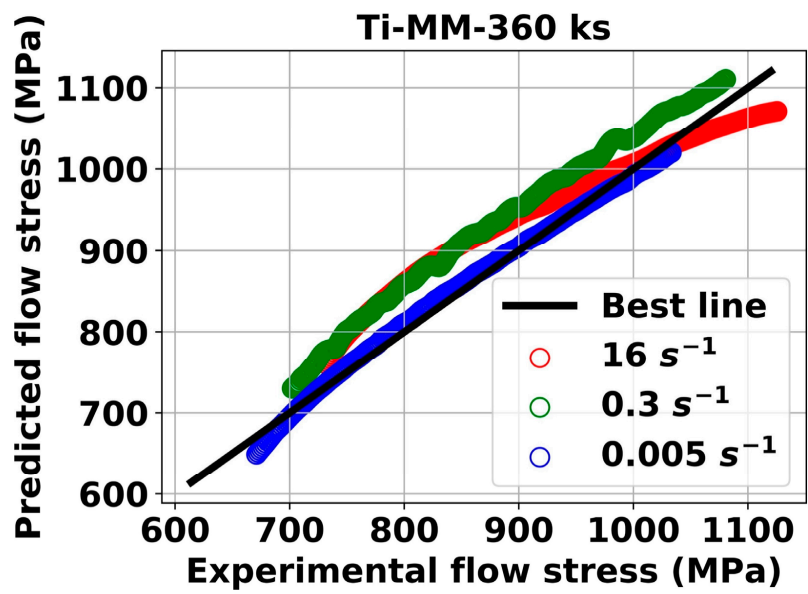

(b)

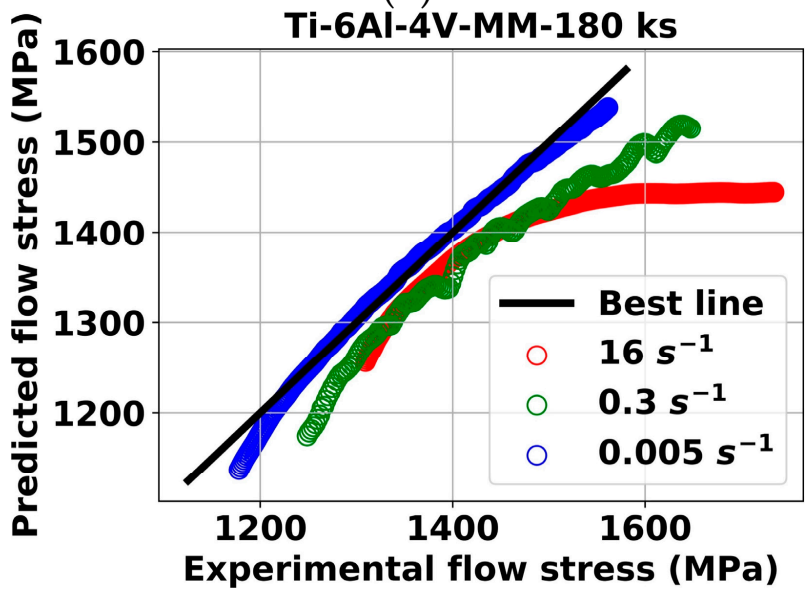

(d)

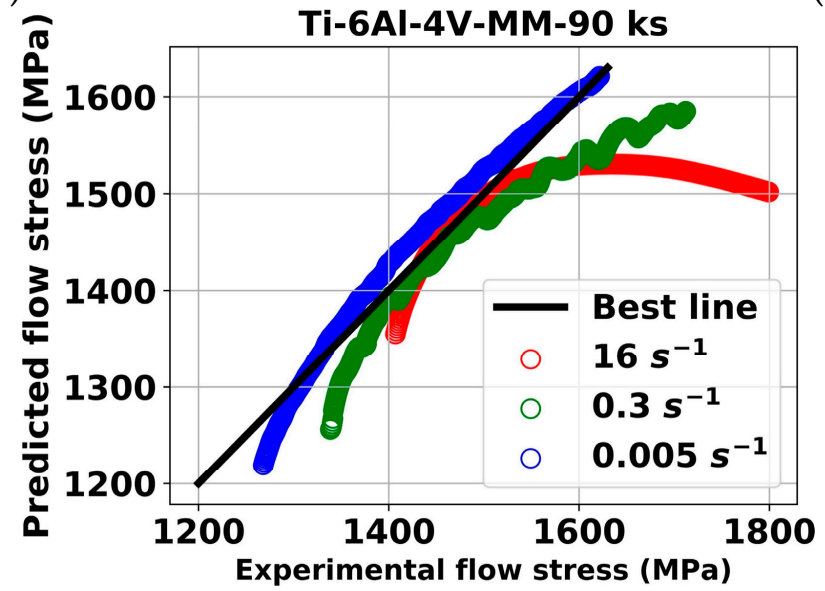

(e)

Figure 8. Predicted flow stress from the Johnson-Cook model versus experimental flow stress of (a) Ti-IP, (b) Ti-MM-360 ks, (c) Ti-6Al-4V-IP, (d) Ti-6Al-4V-MM-90 ks, and (e) Ti-6Al-4V-MM-180 ks.

Considering the modified JC model, the correlation between our experimental flow stress and computed ones are shown in Figure 9. We can see that this model fitted well with our experimental points. As shown in Figure 10, the predicted flow stress from the modified JC model versus the experimental flow stress was close to the line with a slope equal to one. The difference was more pronounced at a low level of stress regarding the 
Ti-6Al-4V-MM-180 ks and Ti-6Al-4V-MM-90 ks samples and a high level of stress regarding the Ti-MM-360 ks.

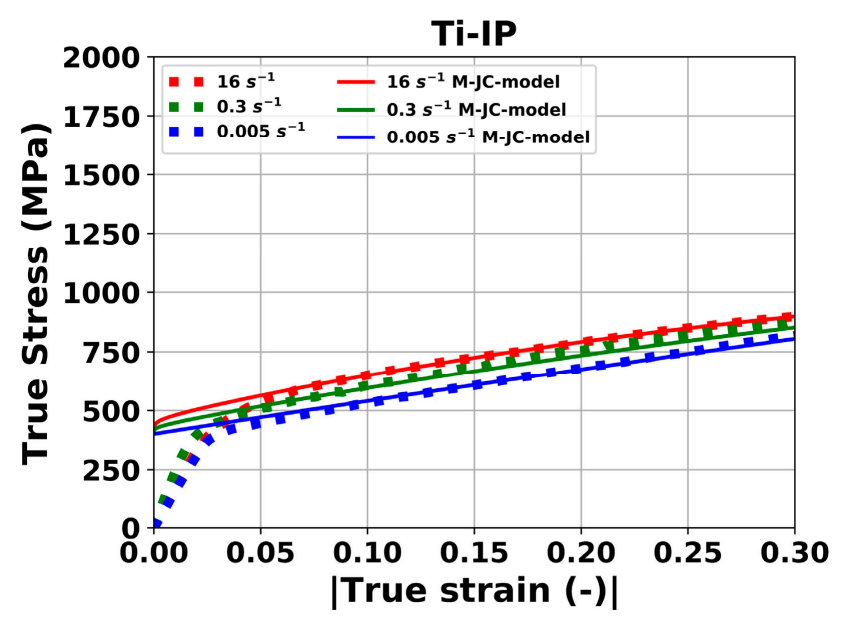

(a)

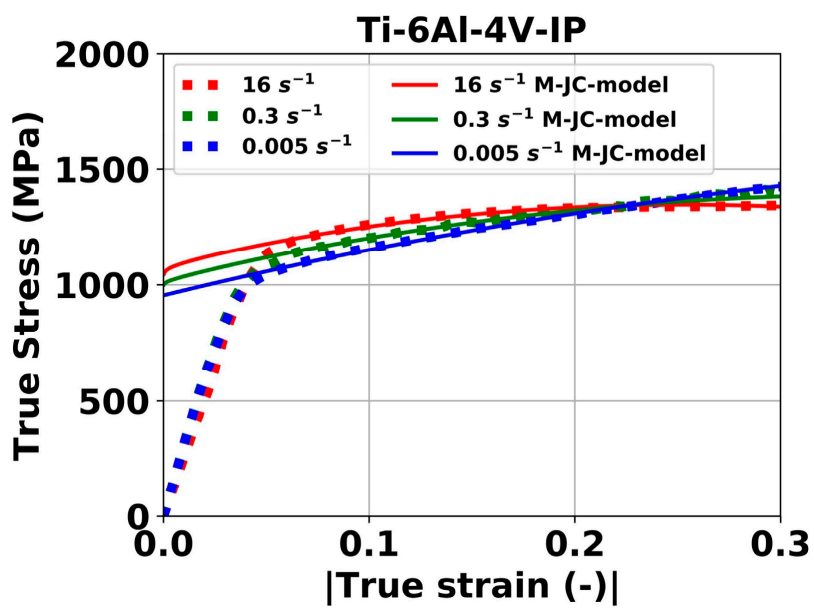

(c)

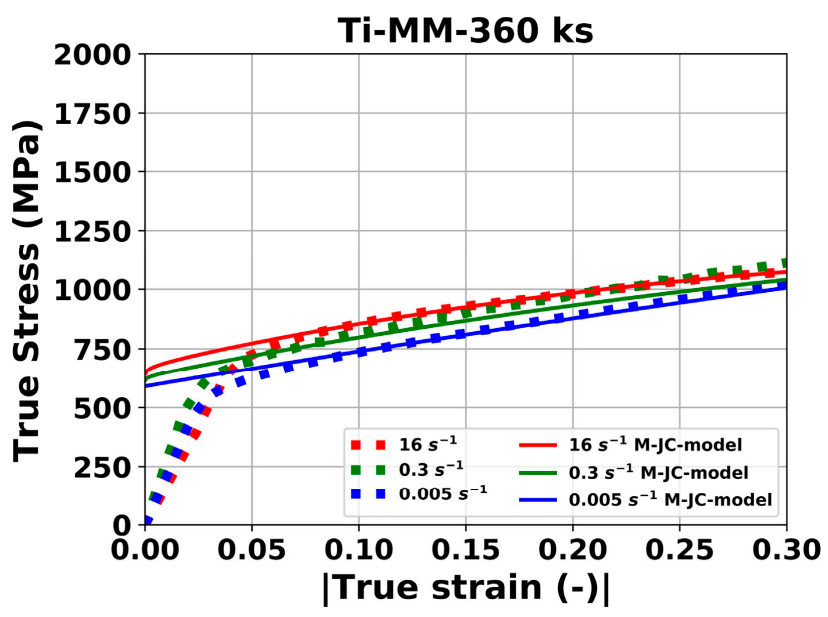

(b)

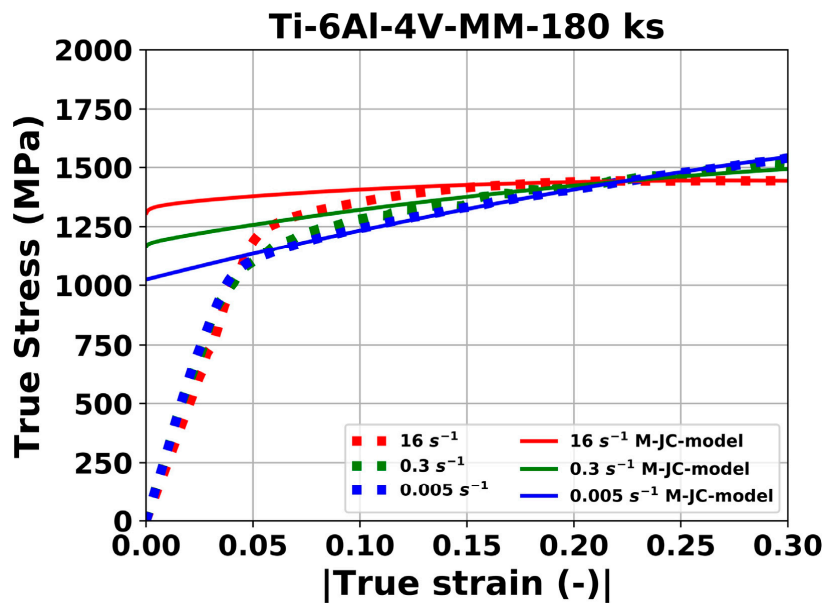

(d)

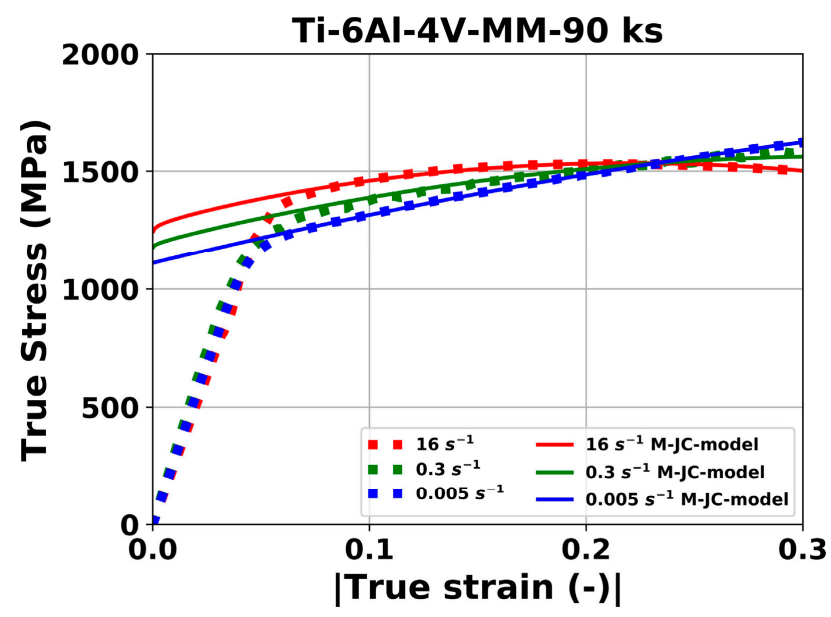

(e)

Figure 9. Experimental (squares) and computed (continuous line) flow stresses by the modified Johnson-Cook (MJC) model of (a) Ti-IP, (b) Ti-MM-360 ks, (c) Ti-6Al-4V-IP, (d) Ti-6Al-4V-MM-90 ks, and (e) Ti-6Al-4V-MM-180 ks. 


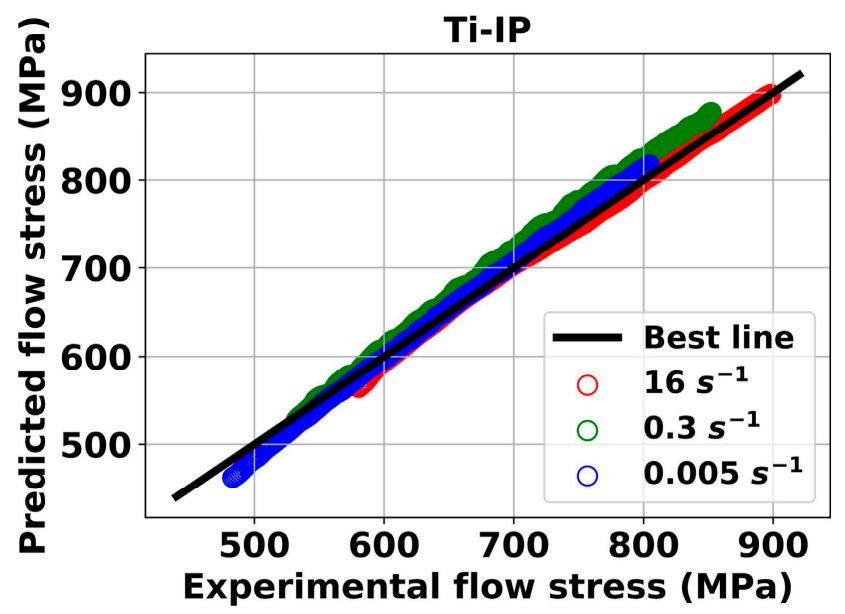

(a)

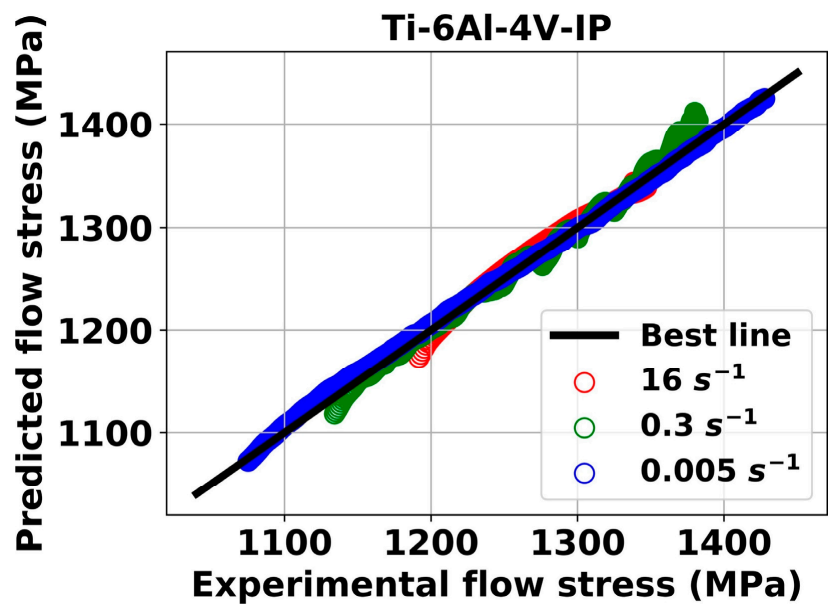

(c)

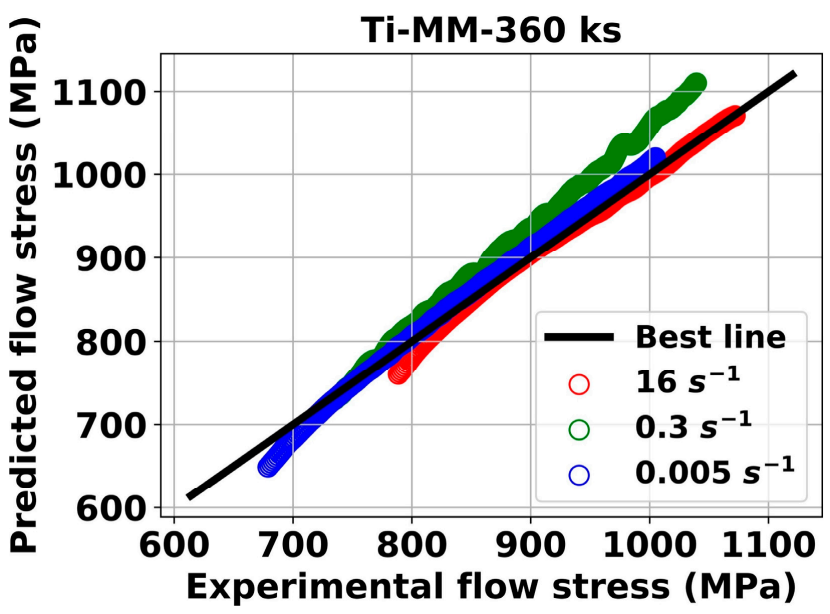

(b)

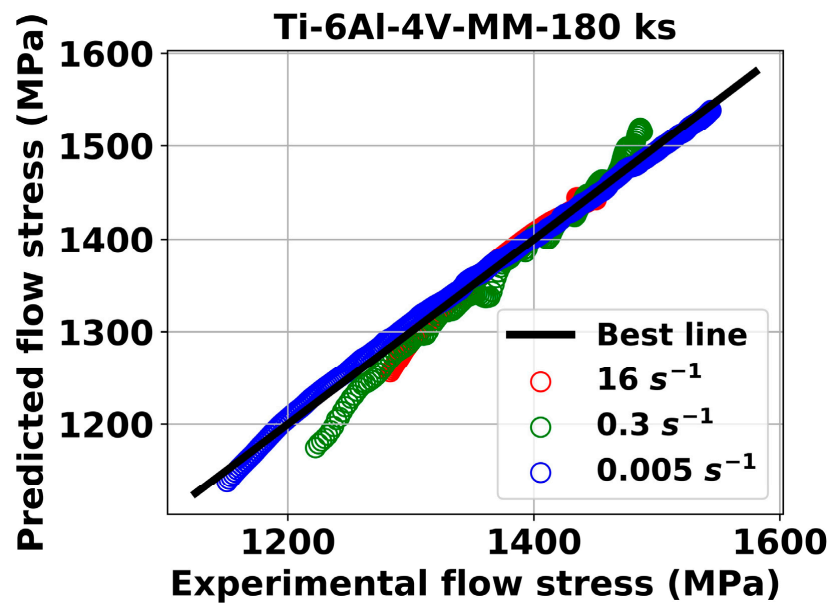

(d)

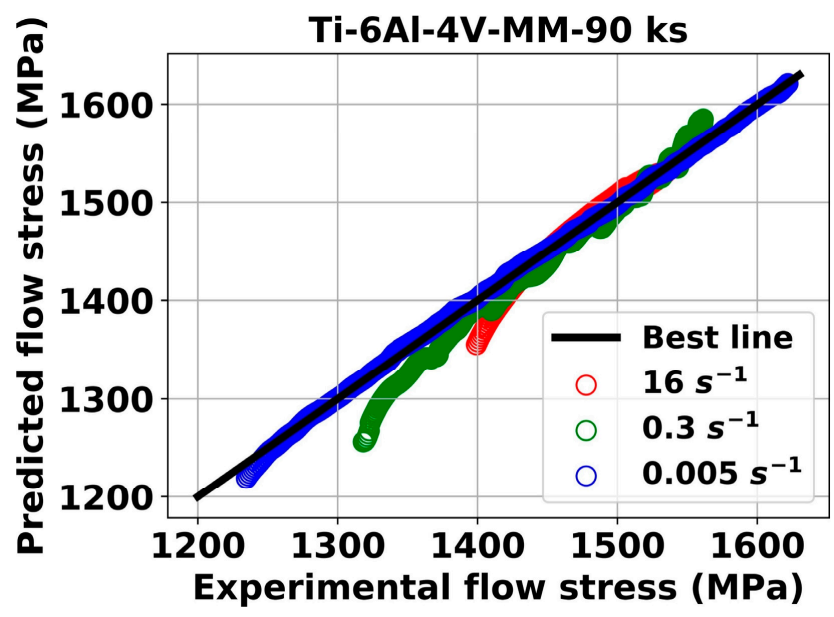

(e)

Figure 10. Predicted flow stress from the modified Johnson-Cook (MJC) model versus experimental flow stress of (a) Ti-IP, (b) Ti-MM-360 ks, (c) Ti-6Al-4V-IP, (d) Ti-6Al-4V-MM-90 ks, and (e) Ti-6Al-4V-MM-180 ks. 


\subsubsection{Accuracy Analysis}

Two constitutive models were considered in this work. The JC and MJC models' predictability was evaluated considering the average absolute relative error (AARE) and the correlation coefficient $(R)$. $R$ corresponds to the strength of the linear relationship between two series of data, while AARE was considered to determine models' predictability data series, defined as follows.

$$
\begin{gathered}
R=\frac{\sum_{i=1}^{i=N}\left(\sigma_{\mathrm{e}}^{i}-\bar{\sigma}_{\mathrm{e}}\right)\left(\sigma_{\mathrm{p}}^{i}-\bar{\sigma}_{\mathrm{p}}\right)}{\sqrt{\sum_{i=1}^{i=N}\left(\sigma_{\mathrm{e}}^{i}-\bar{\sigma}_{\mathrm{e}}\right)^{2} \sum_{i=1}^{i=N}\left(\sigma_{\mathrm{p}}^{i}-\bar{\sigma}_{\mathrm{p}}\right)^{2}}} \\
\operatorname{AARE}(\%)=\frac{1}{N} \sum_{i=1}^{i=N}\left|\frac{\sigma_{\mathrm{e}}^{i}-\sigma_{\mathrm{p}}^{i}}{\sigma_{\mathrm{e}}^{i}}\right| \times 100
\end{gathered}
$$

where $\sigma_{\mathrm{e}}^{i}$ and $\sigma_{\mathrm{p}}^{i}$ are respectively the experimental data and computed results. $\bar{\sigma}_{\mathrm{e}}$ represents the average of $\sigma_{\mathrm{e}}^{i}$ while $\bar{\sigma}_{\mathrm{p}}$ is the average of $\sigma_{\mathrm{p}}^{i}$. N represents the total number of points considered in this work. As an example, Li et al. [56] succeeded in comparing three constitutive models with the experimental values regarding a $\mathrm{SnSbCu}$ alloy thanks to these parameters. Computed $R$ and AARE values are shown in Table 5, for the JC model, and Table 6, for the MJC model.

Table 5. Computed correlation coefficient $(R)$ and average absolute relative error (AARE) values considering the Johnson-Cook constitutive model of the samples.

\begin{tabular}{ccc}
\hline Parameter & $\boldsymbol{R}$ & AARE (\%) \\
\hline Ti-IP & 0.97 & 3.22 \\
\hline Ti-MM-360 ks & 0.97 & 3.52 \\
\hline Ti-6Al-4V-IP & 0.91 & 2.95 \\
\hline Ti-6Al-4V-MM-90 ks & 0.87 & 5.29 \\
\hline Ti-6Al-4V-MM-180 ks & 0.88 & 9.67 \\
\hline
\end{tabular}

Table 6. Computed $R$ and AARE values considering the modified Johnson-Cook constitutive model of the samples.

\begin{tabular}{ccc}
\hline Parameter & $\boldsymbol{R}$ & AARE (\%) \\
\hline Ti-IP & 0.98 & 1.42 \\
\hline Ti-MM-360 ks & 0.98 & 1.83 \\
\hline Ti-6Al-4V-IP & 0.98 & 0.43 \\
\hline Ti-6Al-4V-MM-90 ks & 0.97 & 0.87 \\
\hline Ti-6Al-4V-MM-180 ks & 0.98 & 0.56 \\
\hline
\end{tabular}

The highest $R$ value of the modified model (MJC) was 0.98 . The smallest value of $R$ was 0.87 and was obtained with the JC model for the Ti-6Al-4V-MM-180 ks alloy. Considering all the samples, the $R$ value was always higher with the MJC model than the JC one. The $A A R E$ of the JC model was again always the highest compared with the MJC one. This meant that the modified model (MJC) could satisfactorily track the flow behavior of the harmonic and non-harmonic Ti and Ti-6Al-4V alloys and anticipate the flow stress at different strain rates and strain ranges.

\section{Conclusions}

Homogeneous and harmonic structure-designed Pure Ti and Ti-6Al-4V alloys were studied in this work. The initial microstructure and mechanical properties were investigated via room temperature compression tests at $0.005 \mathrm{~s}^{-1}, 0.3 \mathrm{~s}^{-1}$, and $16 \mathrm{~s}^{-1}$. A m 
odified Johnson-Cook model was compared with the well-known Johnson-Cook model. The results were as follows:

- As expected, due to the mechanical milling process, the grain size of the Ti and Ti-6Al-4V alloys decreased significantly.

- Vickers hardness of the samples increased as the grain size decreased.

- Harmonic microstructures displayed better mechanical properties in terms of compression and Vickers hardness at the investigated strain rates compared to homogeneous ones.

- The $0.2 \%$ offset yield strength $\left(\sigma_{0.2}\right)$ increased with the strain rate.

- Strain rate sensitivity (SRS) exponents of the harmonic and homogeneous samples were relatively close.

- Compared to the classical Johnson-Cook (JC) constitutive model, the proposed modified Johnson-Cook (MJC) model was more adapted to the experimental data as confirmed by the correlation coefficient $(R)$ and average absolute relative error $(A A R E)$ parameters.

- Further; parameters of the MJC flow stress model were determined.

Author Contributions: Conceptualization, T.S., K.H., K.A. and G.D.; methodology, T.S., K.H., K.A. and G.D.; software, T.S., K.H., G.H. and H.M.; validation, T.S., K.H., G.H., H.M., E.M., L.D., M.B., K.A. and G.D.; formal analysis, T.S., K.H., G.H., H.M., K.A. and G.D.; investigation, T.S., K.H., G.H., H.M., K.A. and G.D.; resources, T.S., K.H., G.H., H.M., E.M., L.D., M.B., G.H., H.M. and K.A.; data curation, T.S., K.H., G.H., H.M., K.A. and G.D.; writing-original draft preparation, T.S., G.H. and H.M.; writing-review and editing, T.S., G.H., H.M., K.A. and G.D; visualization, T.S., K.H., G.H., H.M., E.M., L.D., M.B., G.H., H.M., K.A. and G.D.; supervision, T.S., K.A. and G.D.; project administration, T.S. and K.A.; funding acquisition, K.A. All authors have read and agreed to the published version of the manuscript.

Funding: This research was funded by the Promotion of Science Grants-in-Aid for Scientific Research (KAKENHI) numbers JP18K18962 and JP18H05256.

Data Availability Statement: The data presented in this study are available on reasonable request from the corresponding author. The data are not publicly available due to the fact that the data are part of an ongoing investigation.

Acknowledgments: The Promotion of Science Grants-in-Aid for Scientific Research (KAKENHI) are gratefully acknowledged.

Conflicts of Interest: The authors declare no conflict of interest.

\section{References}

1. Motsi, G.T.; Guillemet-Fritsch, S.; Chevallier, G.; Shongwe, M.B.; Olubambi, P.A.; Estournes, C. Microstructural evolution and mechanical properties of pure titanium powders processed by spark plasma sintering. Powder Technol. 2019, 345, 415-424. [CrossRef]

2. Welsch, G.; Boyer, R.; Collings, E. Materials Properties Handbook: Titanium Alloys; ASM International: Almere, The Netherlands, 1993.

3. Fang, Y.; Jiang, X.; Song, T.; Mo, D.; Luo, Z. Pulsed laser welding of Ti-6Al-4V titanium alloy to AISI 316L stainless steel using $\mathrm{Cu} / \mathrm{Nb}$ bilayer. Mater. Lett. 2019, 244, 163-166. [CrossRef]

4. Arrazola, P.J.; Garay, A.; Iriarte, L.M.; Armendia, M.; Marya, S.; Le Maître, F. Machinability of titanium alloys (Ti6Al4V and Ti555.3). J. Mater. Process. Technol. 2009, 209, 2223-2230. [CrossRef]

5. Estrin, Y.; Vinogradov, A. Extreme grain refinement by severe plastic deformation: A wealth of challenging science. Acta Mater. 2013, 61, 782-817. [CrossRef]

6. Hall, E.O. The deformation and ageing of mild steel: III Discussion of results. Proc. Phys Soc. Lond. B 1951, 64, 747. [CrossRef]

7. Petch, N.J. The Cleavage Strength of Polycrystals. J. Iron Steel Inst. 1953, 174, 25-28.

8. Chong, Y.; Deng, G.; Gao, S.; Yi, J.; Shibata, A.; Tsuji, N. Yielding nature and Hall-Petch relationships in Ti-6Al-4V alloy with fully equiaxed and bimodal microstructures. Scr. Mater. 2019, 172, 77-82. [CrossRef]

9. Musin, F.; Kaibyshev, R.; Motohashi, Y.; Itoh, G. High strain rate superplasticity in a commercial Al-Mg-Sc alloy. Scr. Mater. 2004, 50, 511-516. [CrossRef]

10. Liu, Y.; Cai, S.; Xu, F.; Wang, Y.; Dai, L. Enhancing strength without compromising ductility in copper by combining extrusion machining and heat treatment. J. Mater. Process. Technol. 2019, 267, 52-60. [CrossRef] 
11. Dutel, G.D.; Tingaud, D.; Langlois, P.; Dirras, G. Nickel with multimodal grain size distribution achieved by SPS: Microstructure and mechanical properties. J. Mater. Sci. 2012, 47, 7926-7931. [CrossRef]

12. Sadat, T.; Dirras, G.; Tingaud, D.; Ota, M.; Chauveau, T.; Faurie, D.; Vajpai, S.; Ameyama, K. Bulk Ni-W alloys with a compositelike microstructure processed by spark plasma sintering: Microstructure and mechanical properties. Mater. Des. 2016, 89, 1181-1190. [CrossRef]

13. Gu, J.; Zhang, L.; Tang, Y.; Song, M.; Ni, S.; An, X.; Du, Y.; Li, Z.; Liao, X. Improving the strength and retaining the ductility of microstructural graded coarse-grained materials with low stacking fault energy. Mater. Des. 2018, 160, 21-33. [CrossRef]

14. Vajpai, S.K.; Ota, M.; Watanabe, T.; Maeda, R.; Sekiguchi, T.; Kusaka, T.; Ameyama, K. The Development of High Performance Ti-6Al-4V Alloy via a Unique Microstructural Design with Bimodal Grain Size Distribution. Metall. Mater. Trans. A Phys. Metall. Mater. Sci. 2015, 46, 903-914. [CrossRef]

15. Ota, M.; Vajpai, S.K.; Imao, R.; Kurokawa, K.; Ameyama, K. Application of High Pressure Gas Jet Mill Process to Fabricate High Performance Harmonic Structure Designed Pure Titanium. Mater. Trans. 2015, 56, 154-159. [CrossRef]

16. Osaki, K.; Kikuchi, S.; Nakai, Y.; Kawabata, M.O.; Ameyama, K. The effects of thermo-mechanical processing on fatigue crack propagation in commercially pure titanium with a harmonic structure. Mater. Sci. Eng. A 2020, 773, 138892. [CrossRef]

17. Vajpai, S.K.; Ota, M.; Zhang, Z.; Ameyama, K. Three-dimensionally gradient harmonic structure design: An integrated approach for high performance structural materials. Mater. Res. Lett. 2016, 4, 191-197. [CrossRef]

18. Dirras, G.; Ota, M.; Tingaud, D.; Ameyama, K.; Sekiguchi, T. Microstructure evolution during direct impact loading of commercial purity $\alpha$-titanium with harmonic structure design: Direct impact loading of pure harmonic $\alpha$-Ti. Mater. Tech. 2015, 103. [CrossRef]

19. Guennec, B.; Ishiguri, T.; Kawabata, M.O.; Kikuchi, S.; Ueno, A.; Ameyama, K. Investigation on the durability of Ti-6Al-4V alloy designed in a harmonic structure via powder metallurgy: Fatigue behavior and specimen size parameter issue. Metals 2020, 10, 636. [CrossRef]

20. Nakai, Y.; Kikuchi, S.; Osaki, K.; Kawabata, M.O.; Ameyama, K. Effects of rolling reduction and direction on fatigue crack propagation in commercially pure titanium with harmonic structure. Int. J. Fatigue 2021, 143, 106018. [CrossRef]

21. Sharma, B.; Dirras, G.; Ameyama, K. Harmonic Structure Design: A Strategy for Outstanding Mechanical Properties in Structural Materials. Metals 2020, 10, 1615. [CrossRef]

22. Watanabe, T.; Maeda, R.; Kurokawa, K.; Ota, M.; Vajpai, S.K.; Ameyama, K. Harmonic structure design of Ti-6Al-4V alloy by High-pressure gas milling process. Adv. Mater. Process. Technol. 2016, 2, 192-201. [CrossRef]

23. Kikuchi, S.; Hayami, Y.; Ishiguri, T.; Guennec, B.; Ueno, A.; Ota, M.; Ameyama, K. Effect of bimodal grain size distribution on fatigue properties of Ti-6Al-4V alloy with harmonic structure under four-point bending. Mater. Sci. Eng. A 2017, 687, 269-275. [CrossRef]

24. Kurokawa, K.; Kawabata, H.; Watanabe, T.; Ota, M.; Vajpai, S.K.; Ameyama, K. Application of High-pressure gas milling process to pure Titanium for harmonic structure design. Adv. Mater. Process. Technol. 2016, 2, 202-208. [CrossRef]

25. Sawangrat, C.; Yamaguchi, O.; Vajpai, S.K.; Ameyama, K. Application of Harmonic Structure Design to Biomedical Co-Cr-Mo Alloy for Improved Mechanical Properties. Mater. Trans. 2014, 55, 99-105. [CrossRef]

26. Dirras, G.; Ueda, D.; Hocini, A.; Tingaud, D.; Ameyama, K. Cyclic shear behavior of conventional and harmonic structuredesigned Ti-25Nb-25Zr $\beta$-titanium alloy: Back-stress hardening and twinning inhibition. Scr. Mater. 2017, 138, 44-47. [CrossRef]

27. Aquino, J.A.M. Heterogeneous microstructure and deformation behavior of an automotive grade aluminum alloy. J. Alloy Compd. 2004, 369, 1. [CrossRef]

28. Suryanarayana, C. Mechanical alloying and milling. Prog. Mater. Sci. 2001, 46, 1-184. [CrossRef]

29. Oke, S.R.; Ige, O.O.; Falodun, O.E.; Okoro, A.M.; Mphahlele, M.R.; Olubambi, P.A. Powder metallurgy of stainless steels and composites: A review of mechanical alloying and spark plasma sintering. Int. J. Adv. Manuf. Technol. 2019, 102, 3271-3290. [CrossRef]

30. Sekiguchi, T.; Ono, K.; Fujiwara, H.; Ameyama, K. New Microstructure Design for Commercially Pure Titanium with Outstanding Mechanical Properties by Mechanical Milling and Hot Roll Sintering. Mater. Trans. 2010, 51. [CrossRef]

31. Sharma, B.; Miyakoshi, M.; Vajpai, S.K.; Dirras, G.; Ameyama, K. Extra-strengthening in a harmonic structure designed pure titanium due to preferential recrystallization phenomenon through thermomechanical treatment. Mater. Sci. Eng. A 2020, 797, 140227. [CrossRef]

32. Radajewski, M.; Decker, S.; Wendler, M.; Krüger, L. Influence of solution annealing on microstructure and mechanical properties of a quenched and partitioned steel matrix composite processed by SPS. Mater. Sci. Eng. A 2021, 799, 140277. [CrossRef]

33. Sadat, T.; Faurie, D.; Tingaud, D.; Mocuta, C.; Thiaudière, D.; Dirras, G. Fracture behavior of Ni-W alloy probed by in situ synchrotron X-ray diffraction. Mater. Lett. 2019, 239, 116-119. [CrossRef]

34. Sadat, T.; Faurie, D.; Thiaudière, D.; Mocuta, C.; Tingaud, D.; Dirras, G. Lattice strain evolutions in Ni-W alloys during a tensile test combined with synchrotron x-ray diffraction. Materials 2020, 13, 4027. [CrossRef] [PubMed]

35. Sadat, T.; Hocini, A.; Lilensten, L.; Faurie, D.; Tingaud, D.; Dirras, G. Data on the impact of increasing the W amount on the mass density and compressive properties of Ni-W alloys processed by spark plasma sintering. Data Br. 2016, 7, 1405-1408. [CrossRef] [PubMed]

36. Zhou, T.; Wang, G.; Yang, Y.; Li, Y.; Shuai, M. Identification of Multiple Parameters of the Bammann-Chiesa-Johnson Constitutive Model with Comprehensive Experiments for Pure Aluminum. J. Mater. Eng. Perform. 2020, 29, 1262-1271. [CrossRef] 
37. Khare, S.; Kumar, K.; Choudhary, S.; Singh, P.K.; Verma, R.K.; Mahajan, P. Determination of Johnson-Cook Material Parameters for Armour Plate Using DIC and FEM. Met. Mater. Int. 2020. [CrossRef]

38. Niu, L.; Cao, M.; Liang, Z.; Han, B.; Zhang, Q. A modified Johnson-Cook model considering strain softening of A356 alloy. Mater. Sci. Eng. A 2020, 789, 139612. [CrossRef]

39. Chiyatan, T.; Uthaisangsuk, V. Mechanical and fracture behavior of high strength steels under high strain rate deformation: Experiments and modelling. Mater. Sci. Eng. A 2020, 779, 139125. [CrossRef]

40. Tang, W.; Liu, S.; Liu, Z.; Kang, S.; Mao, P.; Guo, H. High strain rate compression deformation mechanism and constitutive equation of fine grained Mg-7Gd-5Y-1.2Nd-0.5Zr alloy at different temperatures. Mater. Sci. Eng. A 2020, 780, 139208. [CrossRef]

41. Zhang, F.; Liu, Z.; Yang, M.; Su, G.; Zhao, R.; Mao, P.; Wang, F.; Sun, S. Microscopic mechanism exploration and constitutive equation construction for compression characteristics of AZ31-TD magnesium alloy at high strain rate. Mater. Sci. Eng. A 2020, 771, 138571. [CrossRef]

42. Bammann, D.J. An internal variable model of viscoplasticity. Int. J. Eng. Sci. 1984, 22, 1041-1053. [CrossRef]

43. Zerilli, F.J.; Armstrong, R.W. Dislocation-mechanics-based constitutive relations for material dynamics calculations. J. Appl. Phys. 1987, 61, 1816-1825. [CrossRef]

44. Bodner, S.R. Constitutive Equations for Dynamic Material Behavior. Mech. Behav. Mater. Dyn. Loads 1968. [CrossRef]

45. Johnson, G.R.; Cook, W.H. Fracture characteristics of three metals subjected to various strains, strain rates, temperatures and pressures. Eng. Fract. Mech. 1985, 21, 31-48. [CrossRef]

46. Wang, J.; Yuan, X.; Jin, P.; Ma, H.; Shi, B.; Zheng, H. Study on modified Johnson-Cook constitutive material model to predict the dynamic behavior Mg-1Al-4Y alloy. Mater. Res. Express 2020, 7. [CrossRef]

47. Shon, J.H.; Park, J.M.; Cho, K.S.; Hong, J.K.; Park, N.K.; Oh, M.H. Effects of various sintering methods on microstructure and mechanical properties of CP-Ti powder consolidations. Trans. Nonferrous Met. Soc. China 2014, 24, s59-s67. [CrossRef]

48. Froes, F.H. Titanium: Alloying. Encycl. Mater. Sci. Technol. 2001, 2001, 9361-9364. [CrossRef]

49. Ren, Y.; Yu, X.; Tan, C.; Li, X. Dynamic mechanical properties and adiabatic shearing behavior of the shock prestrained Ti-6Al-4V alloy having bimodal microstructure. J. Alloy. Compd. 2019, 773, 1054-1063. [CrossRef]

50. Hall, E.O. Variation of Hardness of Metals with Grain Size. Nature 1954, 173, 948-949. [CrossRef]

51. Shah, F.A.; Trobos, M.; Thomsen, P.; Palmquist, A. Commercially pure titanium (cp-Ti) versus titanium alloy (Ti6Al4V) materials as bone anchored implants-Is one truly better than the other? Mater. Sci. Eng. C 2016, 62, 960-966. [CrossRef]

52. Tahreen, N.; Chen, D.L.; Nouri, M.; Li, D.Y. Effects of aluminum content and strain rate on strain hardening behavior of cast magnesium alloys during compression. Mater. Sci. Eng. A 2014, 594, 235-245. [CrossRef]

53. Lee, M.S.; Hyun, Y.T.; Jun, T.S. Global and local strain rate sensitivity of commercially pure titanium. J. Alloys Compd. 2019, 803, 711-720. [CrossRef]

54. Vigié, H.; De Paula, T.; Surand, M.; Viguier, B. Low temperature strain rate sensitivity of titanium alloys. Solid State Phenom. 2017, 258, 570-573. [CrossRef]

55. Guo, Z.; Liu, R.; Wang, C.T.; He, Y.; He, Y.; Ma, Y.; Hu, X. Compressive Mechanical Properties and Shock-Induced Reaction Behavior of a Ti-29Nb-13Ta-4.6Zr Alloy. Met. Mater. Int. 2020, 26, 1498-1505. [CrossRef]

56. Li, T.; Zhao, B.; Lu, X.; Xu, H.; Zou, D. A comparative study on johnson cook, modified Zerilli-Armstrong, and Arrhenius-type constitutive models to predict compression flow behavior of SnSbCu alloy. Materials 2019, 12, 1726. [CrossRef] 